\title{
PARTISIPASI MASYARAKAT DALAM PENGEMBANGAN DAYA TARIK WISATA PANTAI PANDAWA, KABUPATEN BADUNG, DESA KUTUH, KUTA SELATAN
}

\author{
Robertus San \\ Ni Made Oka Karini \\ I GPB Sasrawan Mananda \\ Email : sanrobert750@yahoo.com \\ PS. S1 Industri Perjalanan Wisata \\ Fakultas Pariwisata UNUD
}

\begin{abstract}
ABSTRAK
Partisipasi masyarakat dalam pengembangan daya tarik wisata Pantai Pandawa untuk mengetahui tahapan dan tingkatan partisipasi masyarakat yang diterapkan pada daya tarik wisata Pantai Pandawa, seiring dengan jumlah kunjungan wisatawan yang terus meningkat, mengakibatkan masyarakat Desa Kutuh melakukan partisipasi terlibat lansung dalam seluruh aspek kegiatan pariwisata di daya tarik wisata Pantai Pandawa. Manfaat yang diperoleh adalah manfaat teoritis dan manfaat praktis. Pengambilan data dilakukan di Pantai Pandawa, Desa Kutuh, Kabupaten Badung, Kuta Selatan. Pengumpulan data dilakukan secara observasi, wawancara mendalam, dokumentasi, studi kepustakaan. Data yang diperoleh dengan analisis deskriptif kualitatif.Hasil wawancara menunjukan bahwa bentuk partisipasi masyarakat Desa Kutuh dalam pengembangan daya tarik wisata Pantai Pandawa dapat dilihat dari pengambilan keputusan, pelaksanaan program, evaluasi, dan pembagian hasil. Dapat disarankan partisipasi masyarakat Desa Kutuh perlu ditingkatkan terkait promosi, Sumber Daya Manusia (SDM) masyarakat, pengembangan aktivitas air seperti : snorkeling, gelas bottom, merancang atau mendesain dengan baik atraksi wisata Tarian Kecak yang akan direncanakan, serta memanfaatkan rumput laut sebagai atraksi wisata tersendiri di daya tarik wisata Pantai Pandawa.
\end{abstract}

Kata Kunci: Pantai Pandawa, Partisipasi Masyarakat.

\section{LATAR BELAKANG}

Indonesia memiliki beragam potensi kepariwisataanyang tersebar diberbagai daerah dan masing-masing memiliki keunggulannya tersendiri. Salah satunya adalah potensi kepariwisataan Bali. Pulau Bali terkenal dengan sebutan "Pulau Dewata " merupakan ikon pariwisata Indonesia dan telah menjadi salah satu tujuan wisata dunia yang sangat popular. Keindahan alam, keragaman budaya yang unik dan menarik tak terpisahkan dari sentuhan nilai-nilai religius Hindu serta masyarakat yang ramah, menjadi daya tarik tersendiri bagi masyarakat luar untuk mengunjungi Pulau Dewata. Banyaknya wisatawan yang berkunjung ke Bali baik wisatawan nusantara maupun wisatawan mancanegara merupakan salah satu bukti bahwa Bali masih merupakan destinasi wisata yang sangat potensial dan menjadi andalan utama bagi pariwisata ini dalam sektor pariwisata.

Dalam usaha pengembangan daya tarik wisata tentu saja menjadi tanggung jawab seluruh stakeholder (pemerintah, pengusaha dari bidang pariwisata maupun masyarakat). Cukup banyak usaha-usaha yang telah dilaksanakan oleh pemerintah maupun

swasta, terutama dalam bentuk pemberian informasi-informasi kepada wisatawan (domestik ataupun mancanegara) tentang kondisi wilayah yang kondusif. Sedangkan peran masyarakat (terutama sekitar lokasi wisata) cukup terlihat terutama dalam hal menjaga keamanan dan 
kenyamanan di wilayah sekitar. Disinilah peran masyarakat belum terlalu optimal, masyarakat disekitar lokasi pariwisata sebenarnya memiliki potensi yang sangat besar terutama dalam hal menjaga keberlanjutan keberadaan daya tarik wisata tersebut. Keterlibatan masyarakat secara aktif tentu saja akan memberikan nilai yang baik bagi pemerintah, swasta maupun masyarakat sendiri.

Pantai Pandawa adalah salah satu daya tarik wisata baru yang menarik minat para wisatawan baik mancanegara maupun domestik.Aktifitas pariwisata baru berjalan kurang lebih (dua) tahun. Pantai Pandawa terletak di Desa Kutuh Kecamatan Kuta Selatan, Kabupaten Badung, berjarak kurang lebih (tiga) $\mathrm{km}$ dari kawasan Wisata Nusa Dua danPura Uluwatu. Pantai Pandawa menawarkan pemandangan yang indah tebing dipapas tegak, sebagian berundak di kanan kiri jalan, pasir putih bersih dengan air laut yang hijau kebiruan, tipikal pantai-pantai di Kawasan Bukit. Sekitar 1,5 km jalan menuju pantai ini dipagari tebing-tebing kapur yang menjulang tinggi.

Oleh sebab itu, Pantai Pandawa mempunyai potensi yang sangat bagus dalam menarik wisatawan dan tentunya dapat mengahasilkan devisa bagi negara. Pencapaian tersebut tidak terlepas dari peran dan partisipasi masyarakat Desa Kutuh dalam pengembangan dan pembangunan pariwisata di Pantai Pandawa. Partisipasi masyarakat sangat penting dalam pengembangan pariwisata di Pantai Pandawa. Masyarakat dapat memperoleh keuntungan secara langsung dari kegiatan pariwisata tersebut, tidak sekedar merasakan euphoria. Karena itu, akan dikaji mengenai tingkatan dan tahapan partisipasi masyarakat dalam pengembangan daya tarik wisata Pantai Pandawa, dan upaya Tim Penata Pantai Pandawa, dalam meningkatkan partitisipasi di daya tarik wisata. Untuk itu akan dikaji mengenai:

1. Tahap dan tingkatan partisipasi masyarakat lokal dalam pengembangan daya tarik wisata Pantai Pandawa dan.

2. Upaya Tim Penata dalam meningkatkan partisipasi terhadap pengembangan daya tarik wisata Pantai Pandawa.

\section{METODE}

Pengambilan data dilakukan di Kawasan Pantai Pandawa, Kabupaten Badung, Desa Kutuh, Kuta Selatan. Pantai Pandawa berjarak kurang lebih $3 \mathrm{~km}$ dari Kawasan wisata Nusa Dua dan Pura Uluwatu. Definisi Oprasional Variabel yang digunakan adalah tahap dan tingkatan partisipasi masyarakat Pantai Pandawa dan upaya tim penata Pantai Pandawa dalam meningkatkan partisipasi masyarakat. Terdapat dua jenis data yaitu data kualitatif dan kuantitatif, kemudian sumber data yaitu data primer dan data sekunder, dan teknik pengumpulan data yaitu dengan cara observasi, wawancara mendalam, studi kepustakaan dan dokumentasi. Teknik analisis data yang digunakan yaitu teknik analisis deskriptif kuantitatif.

\section{HASIL}

Pantai Pandawa terletak di Desa Kutuh, Kuta Selatan Badung. Berjarak kurang lebih 3 $\mathrm{km}$ dari kawasan Wisata Nusa dua dan Pura Uluwatu. Semula Pantai Pandawa dikenal sebagai Secret Beach, karena lokasinya tersembunyi di balik deretan perbukitan batu yang hanya ditumbuhi semak-belukar. Secret Beach, menurut beberapa warga Desa Kutuh, Pantai Pandawa sudah lama dikenal.Namun, untuk memasuki kawasan ini, melewati jalan yang diapit oleh tebing terjal. Dinamakan Pantai Pandawa, karena pada sisi tebing yang terjal terdapat patung dari Panca Pandawa. Pantai Pandawa merupakan kawasan wisata baru di Kabupaten Badung yang diresmikan pada tanggal 27 Desember 2012.

\section{Potensi Alami Pantai Pandawa}

1. Potensi Tebing

Untuk melengkapi kebutuhan pengunjung agar bisa berlama - lama di seputaran tebing, akan dibangun sebuah cofee sopdengan model minimalis sehinga tidak mengganggu pemandangan, dengan penambahan pembangunan coffe shop ini diharapkan pengunjung dapat menikmati keindahan laut sambil menikmati coffe dan lainnya, serta diharapkan dapat meningkatkan pendapatan Desa Kutuh.

2.Potensi Pesisir dan PasirPutih 
Kawasan pesisir yang cukup Panjang sangat memungkinkan dikelola untuk berbagai kegiatan seperti Penyewaan Longchair, voli Pantai, Outbound, wedding party, Shooting , pementasan atraksi budaya.

1. Kawasan Perairan (Atraksi Wisata Air) Perairan pantai pandawa pada saat ini memiliki berbagai fungsi yang mana oleh desa Adat telah ditetapkan menjadi tiga Zona pemanfaatan yaitu;

a. Zona Budidaya Rumput Laut.

b. Zona Publik Area.

c. Zona Konservasi

2. Parking Area. Sebagai Kawasan Pariwisata yang tidak boleh diabaikan adalah tempat parkir bagi para pengunjung. Berdasarkan wawancara kami dengan tim pengelola bahwa pendapatan terbesar untuk Pandawa saat ini adalah bersumber dari tiket masuk dan parkir. Saat ini telah dibuka area", parkir baru yang terletak di sisi Barat dan Timur pantai pandawa, sebagai solusi mengatasi kekroditan parkir ketika terjadi lonjakan pengunjung dan harapanya, dengan dibukanya lokasi parkir ini dapat Wisatawan bisa menyebar ke seluruh kawasan Pantai Pandawa.

3. Sunrise adalah merupakan Panorama Alam Pagi Hari yang sangat Exotiq sering menjadi moment sangat indah. Pantai Pandawa memiliki Sunrise hampir sepanjang Bulan, yang kedepan dapat dimanfaatkan untuk memperkaya panorama daya tarik wisata pantai Pandawa.

4. Sunset merupakan panorama alam sore hari, moment yang selalu ditunggutunggu oleh pengunjung karena keindahan. Pantai Pandawa yang memiliki pontensi Sunset, dan untuk bulan-bulan tertentu dapat dipadukan dengan pementasan seni tarian kecak.

\section{Potensi Buatan}

Pantai pandawa tidak hanya memiliki potensi alami, tetapi juga potensi buatan. Berikut akan dijelaskan mengenai potensi buatan yang ada di Pantai Pandawa, meliputi:

a. Patung Pandawa
Patung Pandawa merupakan simbol dari nama Pantai ini, patung-patung ini dibangun di dalam tebing sesuai dengan konsep Pandawa Lima terjebak didalam Gua Gala-gala saat berperang melawan para Kurawa.

b. Voli Pantai

Voli Pantai ini juga merupakan potensi wisata buatan berada dibibir Pantai Pandawa, dan dialokasikan di bagian barat Pantai Pandawa, yaitu berada didepan tempat tim pesona bahari yang sarana dan prasarana sudah disediakan oleh tim pesona bahari.

c. Fasilitas

Fasilitas juga merupakan potensi buatan dimana diarea kawasan pantai pandawa, telah tersedia berbagai macam fasilitas yang bisa memenuhi kebutuhan setiap pengunjung yang datang.
a. Restorant (Restoran)
b. Art shop
c. Kios-Kios Penjualan makanan dan minuman
d. Toilet
e. Tempat Spa
f. Tourist Information Center.
g. Sunbed.

\section{PEMBAHASAN \\ Tahapan Partisipasi}

Mengacu pada teori baahwa, Bentuk Partisipasi terdiri dari beberapa tahapan yaitu:

Tahap Perencanaan (Participation in decision making)

Parameter yang di ukur dalam Partisipasi Tahap Perencanan adalah Keterlibatan dalam identikasi masalah, perumusan tujuan, dan pengambilan keputusan. Penelitian ini menunjukkan bahwa $70 \%$ masyarakat Desa Kutuh mengaku sudah dilibatkan dalam identikasi masalah dan ikut terlibat dalam pengambilan keputusan terkait pengembangan daya tarik wisata Pantai Pandawa

Tahap Pelaksanan Program (Participation In Implementation)

Parameter yang diukur dalam partisipasi tahap Pelaksanan Program adalah 
1. Keterlibatan di dalam pengelolaan usaha pariwisata di daya tarik wisata Pantai Pandawa, dan kegiatan-kegiatan lain, seperti mempromosikan daya tarik wisata Pantai Pandawa,

2. Pelaksanaan program investasi.

3. Pelaksanaan program pembentukan BUMDA.

4. Pelaksanan Program pengembangan fasilitas.

Tahap Pembagian hasil (Participation in Benfits)

Parameter yang di ukur dalam partisipasi tahap Pembagian hasil adalah

1. Masyarakat Desa Kutuh diberikan kesempatan untuk meminjam uang di LPD (Lembaga Pengkreditan Desa) untuk membuka usaha di daya tarik wisata Pantai Pandawa.

2. Memberikan Beasiswa kepada siswa atau mahasiswa yang berprestasi dari Desa Kutuh.

3. Membagi secara merata kesetiap banjar, sesuai kebutuhan dan keperluan mereka.

Tahap Evaluasi (Participation In Evaluation)

Parameter yang diukur dalam partisipasi tahap evaluasi adalah kehadiran masyarakat dalam rapat evaluasi yang di laksanakan sebulan sekali. Masyarakat Desa Kutuh sangat antusias dalam menghadiri pertemuan evaluasi.

\section{Tingkatan Partisipasi masyarakat}

Tingkatan Partisiasi Masyarakat

Partisipasi masyarakat Desa Kutuh dalam pengembangan pariwisata di Pantai Pandawa, idealnya mengacu pada pengertian pariwisata diatas. Selain mengacu pada teori diatas, partisipasi masyarakat di daya tarik wisata Pantai Pandawa, perlu dikaji berdasarkan tingkatan partisipasi. Untuk Mengetahui tingkatan partisipasi masyarakat di daya tarik wisata Pantai Pandawa, berikut akan dijabarkan

\section{Partisipasi Manipulasi (Manipulative Participation)}

Partisipasi masyarakat Desa Kutuh pada tingkat manipulasi ini adalah Tim Penata Pantai Pandawa, selalu memberikan informasi dan kesempatan kepada masyarakat untuk berpartisipasi dalam pengambilan keputusan maupun dalam pelakssanan program.

\section{Partisipasi Pasif(Passive Participation) \\ Partisipasi}

Masyarakat Desa Kutuh pada tingkat ini adalah masyarakat cepat mendapatkan informasi mengenai suatu hal yang terjadi, tidak terbatas pada orang yang dianggap mampu atau profesional, tetapi melibatkan seluruh komponen masyarakat.

\section{Partisipasi Melalui Konsultasi (Participation by Consultation)}

Partisipasi masyarakat Desa Kutuh pada tigkka konsultasi adalah masyarakat mengambil bagian pada kegiatan pariwisata seperti perumusan kebijakan, pelkasanan program terlebih dahulu melakukan konsultasi dengan pihak Desa Kutuh

Partisipasi interaktif (Interactive Participation)

Partisipasi masyarakat Desa Kutuh pada tingkat interaktif ini adalah masyarakat dilibatkan lansung pada pelaksanan program. Mayarakat Desa Kutuh mempunyai kewajibaan dalam kegiatan tersebut.

Partisipasi Untuk Insentif (Participation for Material Incentives)

Partisipasi masyarakat Desa Kutuh, pada tingkat insentif ini adalah masyarakat menyumbangkan tenagakerja dan mendapatkan upah, dalam proses pembuaatan fasilitas, pembersihan dan kegitan lain seperti, kegiatan (Gathering Pandawa beach) yang melibatkan seluruh komponen masyarakat.

\section{Partisipasi Fungsional (Funcitional Participation)}

Partisipasi masyarakat Desa Kutuh pada tingkat fungsional ini adalah pengambilan keputusan bersifat lokal oleh masyarakat.Tim Penata Pantai Pandawa sebagai pengarah dalam melaksanakan kegiatan tersebut.

\section{Partisipasi inisiatif (Self-Mobilication) \\ Partisipasi masyarakat Desa Kutuh Pada tingkat Inisiatif ini adalah masyarakat melaksanakan program atau kegiatan pariwisata di Pantai Pandawa, seperti pembersihan berdasarkan inisiatif sendiri tanpa dorongan dari pihak lain.}




\section{SIMPULAN}

Hasil pembahasan diatas dapat disimpulkan sebagai berikut.

Pengembangan daya tarik wisata Pantai Pandawa, tidak terlepas dari keikutsertaan masyarakat lokal. Masyarakat sudah mengambil bagian dalam peroses partisipasi. Adapun tahapan dan Tingkatan partisipasi masyarakat di daya tarik wisata Pantai Pandawa adalah

1. Tahap pengambilan keputusan, masyarakat sudah berpartisipasi secara maksimal dilihat dari kehadiran dan antusias masyarakat pada saat pertemuan atau kehadiran rapat.

2. Tahap pelaksanan program, partisipasi masyarakat dapat dilihat dalam pengelolaan usaha pariwisata yang ada di daya tarik wisata Pantai Pandawa. Dalam hal ini masyarakat telah mengambil bagian dalam pengelolaan usaha.

3. Tahap pembagian hasil, masyarakat sudah merasakan lansung pendapatan dari daya tarik wisata Pantai Pandawa, misalnya dengan memberikan beasiswa kepada anakanak SMA dan Mahasiswa yang berprestasi dari Desa Kutuh, membagikan sama rata pada tiap banjar sesuai dengan keperluan.

4. Tahap evaluasi, Masyarakat sudah mengambil bagian dalam pertemuan evaluasi yang dilaksanakan sebulan ataupun setahun sekali.

Tingkatan partisipasi Masyarakat Desa Kutuh terdiri dari Partisipasi manipulasi, Partisipasi pasif, Partisipasi konsultasi, Partisipasi insentif, Partisipasi fungsional, Partisipasi interaktif, Partisipasi inisiatif.

\section{SARAN}

Dari hasil yang telah dipaparkan diatas maka terdapat beberapa saran yang dapat diberikan yang sekiranya dapat membantu serta bermamfaat bagi pihak-pihak yang berkepentingan:

1. Kegiatan promosi, diharapkan kepada pihak pengelola agar dengan gencar melakukan promosi baik untuk wisatawan domistik maupun wisatawan mancaegara, supaya jumlah kunjungan wisatawan semakin meningkat.
2. Kendala masyarakat dalam hal pengetahuan dan bahasa asing, diharapkan Tim pengelola lebih fokus melatih, membina dan memberikan sosialisasi kepada masyarakat dengan mendatangkan pelaku pariwisata yang berkompeten sesering mungkin, sehingga masyarakat lebih profesional dalam bekerja.

3. Tim pengelola Pantai Pandawa lebih meningkatkan atau mengembangkan kegiatan aktivitas air seperti snorkling, dan sebagainya disesuaikan dengan permintaan wisatawan, supaya masyarakat Desa Kutuh lebih banyak mendapatkan keuntungan.

4. Tim pengelola Pantai Pandawa merancang dan mendesain dengan baik atraksi wisata tarian, sehingga wisatawan lebih tertarik mengunjungi daya tarik wisata Pantai Pandawa.

5. Tim pengelola Pantai Pandawa mensosialisasikan keberadaan rumput laut sebagai daya tarik tersendiri bagi wisatawan, sehingga masyarakat tetap yang berkerja menjadi petani rumput laut.

\section{DAFTAR PUSTAKA}

Tim Penataan Pantai Pandawa,2015. Dalam Rencana Kerja, Anggaran Pendapatan Dan Belanja, Managemet Pengelola Kawasan Wisata Pantai Pandawa.

A. Oktami, Dewi A. A. P. 2013.Partisipasi Masyarakat Dalam Pengembangan Objek Wisata Bahari Di Pulau Kapoposang Kabupaten Pangkajenedan Kepulauan.

Elida, Farikhah.2005. Pola Pengembangan Pariwisata Yang Berbasis Masyarakat Di Kepulauan Karimunjawa.

Ernawati, Diyah B, 2012 "Pengembangan Pariwisata Berbasis Masyarakat (Community Based Tourism) yang Berwawasan Lingkungan Hidup",Bandung: Jurnal Pariwisata STIE PAR vol 7 no.l feb 2006.

Slamct,Y.1989. Konsep-konsep Dasar PartisipasiSosial. Pusat Antar UniversitasStudiSosial, Universitas Gadjah Mada, Yogyakarta 
Jurnal IPTA

ISSN : 2338-8633

Vol. 4 No. 1, 2016

Santos Guterres, Cipriana Dos. 2014. Pengembangan Daya Tarik Wisata berbasis masyarakat Di Pantai Votuvou, Distrik LiQuisa, Timor Leste.International Journal Of Tourism, Publish by Universitas Udayana, Volume 01, Nomor 01 Juli 2014.

Yoeti. Oka A.1997. Perencanan dan pengembangan Pariwisata: Bandung Angkasa. 